\title{
Historical and Epistemological Reflections on the Culture of Machines around the Renaissance: How Science and Technique Work?
}

\author{
Raffaele Pisano \\ Department of Physics, \\ University of Lille1, \\ Bât. P5 bis, \\ Villeneuve d'Ascq F-59655, France \\ E-mail: pisanoraffaele@iol.it

\section{Paolo Bussotti} \\ Alexander von Humboldt Foundation \\ Berlin, Germany \\ Via Paolo Lilla 66, \\ Livorno I-57122, Italy \\ E-mail: paolobussotti66@gmail.com
}

\begin{abstract}
This paper is divided into two parts, this being the first one. The second is entitled 'Historical and Epistemological Reflections on the Culture of Machines around Renaissance: Machines, Machineries and Perpetual Motion' and will be published in Acta Baltica Historiae et Philosophiae Scientiarum in 2015. Based on our recent studies, we provide here a historical and epistemological feature on the role played by machines and machineries. Ours is an epistemological thesis based on a series of historical examples to show that the relations between theoretical science and the construction of machines cannot be taken for granted, a priori. Our analysis is mainly based on the culture of machines around $15^{\text {th }}$ and $17^{\text {th }}$ centuries, namely the epoch of Late Renaissance and Early Modern Age. For this is the period of scientific revolution and this age offers abundant interesting material for researches into the relations of theoretical science/construction of machines as well. However, to prove our epistemological thesis, we will also exploit examples of machines built in other historical periods. Particularly, a discussion concerning the relationship between science theory and the development of science art crafts produced by non-recognized scientists in a certain historical time is presented. The main questions are: when and why did the
\end{abstract}


tension between science (physics, mathematics and geometry ${ }^{1}$ ) give rise to a new scientific approach to applied discipline such as studies on machines and machineries? What kind of science was used (if at all) for projecting machines and machineries? Was science at the time a necessary precondition to build a machine? In the first part we will focus on the difference between AristotelianEuclidean and Archimedean approaches and we will outline the heritage of these two different approaches in late medieval and Renaissance science. In the second part, we will apply our reconstructions to some historical and epistemological problems concerning the relations of science/technology/ constructions of machines. The problem of perpetual motion will play an important role in this context.

Keywords: foundations, machines, machineries, mechanics, perpetual motion, science in context, techniques

\section{Outline}

Generally speaking, science (versus a structured discipline) was born from observation and capacity of abstraction from observed phenomena. It runs (mainly) by means of:

1) Non-natural languages (geometry and mathematics)

2) The application of mathematics and geometry to the natural phenomena, which produced a new discipline called philosophia naturalis (Galileo, Descartes, Newton, and others), nowadays called physics (Pisano 2009a,b,c). Nevertheless, what about machines ${ }^{2}$ ?

In this sense, an a priori relationship between science ${ }^{3}$ and technique/technology was hypothesized, in the secondary literature, for example, as follows: presenting

\footnotetext{
1 Generally speaking, geometry belongs to mathematics. We distinguish between the role of geometry and of other mathematical disciplines (arithmetic, algebra, calculus starting from the $17^{\text {th }}$ century) in our context. Therefore, we simply and historically distinguish between geometry and mathematics, including under this denomination all mathematical branches not belonging to classical definition of geometry.

2 With regard to the definition of machine, we refer to the intuitive conception according to which a machine is a device or a system of devices consisting of fixed and moving parts, which modifies mechanical energy and transforms it in a more useful form. This is enough for our aims. Other studies-with a different approach with respect to our historical/epistemological investigations-concern the history of social reasons of machines drawings traits (e.g., Popplow, 1998; 2001; 2002; 2003; 2004; 2010; see also http:// www.bma.arch.unige.it/it/AUTORI/it_autori_Popplow_M.html).

3 On the relationship of physics and mathematics see, e.g., Pisano, 2011; Pisano \& Bussotti, 2012; 2014b,c; also Pisano \& Casolaro, 2011. On recent research about science and technology see Pisano, 2014.
} 
Raffaele Pisano

Paolo Bussotti

mechanics, machineries, mechanism, religious causes, and philosophy of mechanicism with the idea that the development of science and related technique was a necessary condition to create functioning machines and that, hence, the only possible paradigm of research was the one connecting history of machines with the history of science and technique. The following diagram (Fig. 1 and Fig. 2) summarizes the outline of the problem:

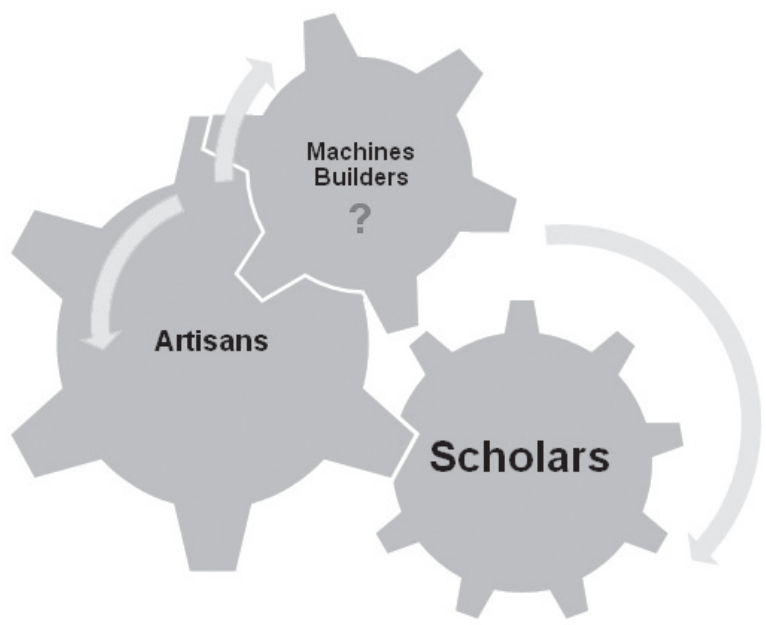

Figure 1. An example of shared knowledge?

From here derives a connected question: Was it possible to build a machine without knowing Aristotle's and Euclid's sciences?

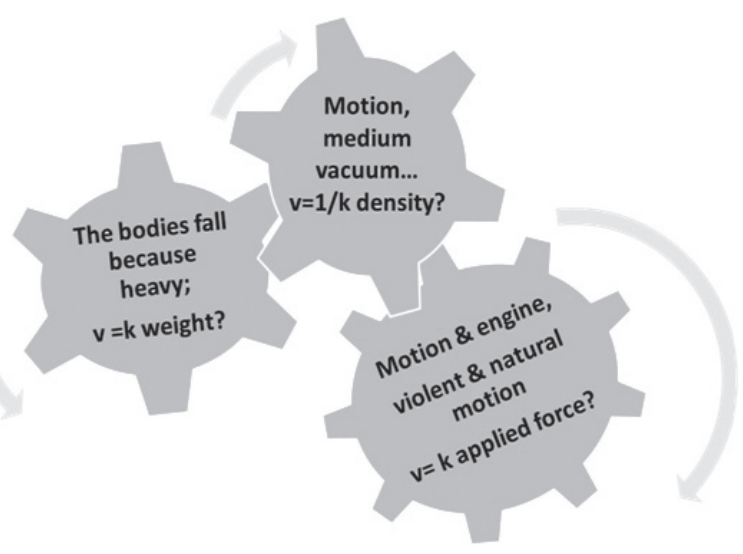

Figure 2. What is the scientific background to project-build a running machine? 
Usually a discussion concerning history and historiography (Kragh, 1987) of science and technique/technology is presented as a discipline within the general history of science. This is thought necessary in order to understand the possible relationship between science and the development of arts and crafts produced by non-recognized scientists at a certain time in history. For example:

- Presenting mechanics and mechanism and then the general importance of machines. The study is within science and technique as a unique technical paradigm of investigation.

- Presenting philosophy of mechanicism to explain traditions, heritage and aims. The study is within philosophy as a unique paradigm of investigation.

- Presenting the role played by religions to explain traditions, heritage and aims. The study is within philosophy as a unique paradigm of investigation.

- Presenting the rationalism of ancient writings as having remarkable impact on Renaissance scholars. The study is within humanism philosophy as a unique paradigm of investigation.

It seems that most scholars offer interesting outlooks of analysis but within a predominant and unique paradigm key of investigation (Pisano, 2009a,b,c). As mentioned above, an a priori existing relationship between science and technique/ technology was proposed. We think that this relation should be discovered $a$ posteriori and case by case, as there is no necessary connection between science and technique/technology.

In the history of scientific ideas, the continuity thesis (from artisans' practice to modern science) generally concerns the hypothesis according to which there is no discontinuity between the intellectual/scientific/practical development in the Middle Ages and the intellectual/scientific developments in the Renaissance, until the early years of the birth of modern science. Thus, the idea of an intellectual/ scientific revolution/discontinuity thesis following the Renaissance would be a myth, according to this interpretation. Ernst Mach (1838-1916), Alexandre Koyré (1892-1962), Pierre Maurice Marie Duhem (1861-1916) and Thomas Kuhn (1922-1996) represent the main accounts around or in opposition on that. For example, Mach focused on the method and foundations:

The fertile methods of thought of Galileo, Huygens, S. Carnot, Mayer, and their peers, are all reducible to the simple but significant perception that purely periodical alterations of one set of circumstances can only constitute 
the source of similarly periodical alterations of a second set of circumstances, not of continuous and permanent alterations. (Mach, [1883]1974, p. 503, line 27)

Duhem popularized the concept of saving the phenomena within continuity thesis. According to this, there is no contrast between medieval and modern thought (Le système du monde: histoire des doctrines cosmologiques de Platon à Copernic, 1913-1959). He tried to show that the Roman Catholic Church had helped foster the development of Western science. His work was prompted by his research into the origins of statics, Les origines de la statique (Duhem, 19051906), in which he encountered the works of medieval mathematicians and philosophers. Duhem (1905-1906, vol. I, part IV, p. 38) concluded that

the mechanics and physics of which modern times are justifiably proud proceed, by an uninterrupted series of scarcely perceptible improvements, from doctrines professed in the heart of the medieval schools.

It is well known that Koyré proposed an opposite thesis based on the revolution/ discontinuity thesis (Pisano \& Gaudiello, 2009; Pisano, Agassi \& Drozdova, 2015, pre-print), relying mainly upon the following key of investigations:

a) The destruction of the cosmos and therefore the disappearance from scienceat least in principle, if not always in fact-of all considerations based on this concept.

b) The geometrization of space, that is, the substitution of the homogeneous and abstract-however now considered as real-dimension of space of the Euclidean geometry for the concrete and differentiated place-continuum of pre-Galilean physics and astronomy (Koyré, 1965, p. 53, 6, line 17).

Kuhn based his research on the idea of scanning scientific structures in the history of science, which can be established as a paradigm or produce a replacement of an old framework (incommensurability) among scientific theories (Kuhn, 1962; 1978).

With regard to our previously outlined question on the builders of machines during the Renaissance, Bertrand Gille (1920-1980) proposed a more precise answer:

All our engineers were men of war. Such statements of the obvious have the uncomfortable habit of often being true. Yet the sixteenth century had passed beyond warlike preoccupations and had constructed a complete technical 
system, just as it had built a new scientific system. More than their quest for deadly power, more than the amusements and the love of images, what has attracted us in these men is the difficult apprenticeship they served in a new world. Much remains to do before we understand the processes of their thought, before we appreciate their hesitations and grasp the nature of their ignorance and their failures. We must underline their gradual distortions of accepted truths, their difficult departures from the traditional paths, in order to give them credit for having [...] unique advance in the history of thought. [...] But the enquiry remains open: it might bring to light other works still languishing in the dust of libraries, it might also provide a more precise analysis of the notebooks which have never been published and which are full of information. (Gille, 1966, p. 240; see also Hall, 1997)

However, as Gille claimed, new studies are necessary.

On our side a historical-epistemological analysis related with the possible (how and when) use of science (physics, mathematics and geometry) in the construction of machines and machineries is necessary. One of the main questions is: When and why did the tension between science (physics, mathematics and geometry) give rise to a new scientific approach to applied discipline such as studies on machines and machineries during the Renaissance and the Early Modern Age?

An investigation on the foundations of science is a significant key to capture the structure of science at that time: it is hence necessary to start from science at that time in order to investigate the role played by theoretical and conceptual frameworks as a possible bridge between science and techniques/technologies within machines and machineries. Thus, what kind of science was used (if at all) for projecting machines and machineries?

\section{Structure of the paper}

As mentioned above, the two correlated papers concern a historicalepistemological reflection on the historical foundations of sciences (physics, geometry and mathematics) related to the relationship among scientific theories (main Aristotelian, Euclidean, Archimedean), non-scientific theories (i.e. a social impact of the imitatio naturae) and machines (artisan, builders, etc.) around the Renaissance. 
This paper is thus divided into three parts:

1. Notes on science and its paradigm structure. In this section, we briefly describe the main features of the science known and produced by scientists until the Renaissance. We aim at understanding whether these features were helpful and used by the builders of machines (first paper).

2. On machines, mechanics and machineries—perpetual motion. In this section, we discuss the role played by mechanics and machineries in machines. The impossibility of perpetual motion is presented as a significant presupposition in the construction of the machines, both from a theoretical and practical standpoint (second paper, first part).

3. No theory, no machine? In this section, we briefly discuss cultural conceptual frameworks of the influence of applied mechanical science for machines (second paper, second part).

4. The references are listed at the end of the two related articles as mentioned above. Nevertheless, both lists of references represent the whole historical and epistemological-philosophical account studied by us. For we consider them as a unique global list of references on the subject proposed by us.

5. Some final remarks conclude the paper.

The discussed correlated reflections are the following:

- What is the cultural background of a common Renaissance scholar?

- What were the beliefs of generalized pseudo-science?

- The doctrine of imitatio naturae.

- What theory did artisans have? Geometry and mathematics?

- Is machine arts and crafts independent from science?

- Could they build a running machine (including the calculation of mechanical advantage) without knowledge of science?

- When did science begin to play a fundamental role in the construction of machines?

- What kind of modelling? 
- The role of perpetual motion machines in the design and implementation.

- The role of scale, friction, and velocity, profile of the machineries-machines.

- Interpretation of phenomena (and many other related social factors).

- It was not possible to apply scientific abstractions (nowadays called applied science) to machines because machines belonged to godly-world-universemachine, so men could not improve or perfect them using science.

- Machines scientifically developed when artisans understood the impossibility of perpetual motion. This was an incentive for the scientists to calculate the efficiency of a machine. This process took place from the $18^{\text {th }}$ century until 1824 (see Carnot's (1786) book on efficiency of heat machines).

Further on, concerning the humanistic and religious aspects correlated with human-scientific-technique activities, we mainly take into account the doctrine of imitatio naturae. Following this point of view, a scientific theory for building machines did not appear strictly necessary because of three main reasons:

- Machines are already part of Godly machine theory, and it is incompatible with corpus of the science.

- In imitatio naturae each effort for perfecting was forbidden. For example, a tree is part of Godly machine, that is an (Aristotelian) primary form, while a catapult obtained by that tree as product is an (Aristotelian) secondary form (e.g., Bacon). ${ }^{4}$

- Men can know only what is artificial. The natural non-artificial phenomena represent an unknown reality for men.

4 The doctrine of imitatio naturae is a very general subject on which a large and profound literature exists. However, ours is a paper on the history of foundations of science related to the relationship between science and technique as in machines. Hence, a general reference to imitatio naturae - as one of the social reasons for the development of the performing machines-expounded in the running text is sufficient for our aims. The reader will find more details in Aristotle, Physica, II, 8, 198a, 15-20; 194a, 21-22; Metereologica, IV, 3, 381b, 6.; Francis Bacon, Historia rei bellicae et artium subserventium [...] with the famous critics to Aristotelian thesis of imitatio naturae. We mention a general assertion by Bacon on the nature and on the imitation of nature drawn from De Dignitate et Augmentis Scientiarum: "I find nature in three different states. She is either free, and follows her ordinary course of development as in the heavens, in the animal and vegetable creation [...] or she is driven out of her ordinary course by the perverseness [...] of matter [...] as in the case of monsters; or lastly, she is put in constraints, molded and made as it were new by art and the hand of man; as in things artificial" (Bacon 1857-1874, IV, p. 294). Generally speaking, on the social aspects of the history and philosophy of sciences a large secondary literature exists; among them we mention Paolo Rossi's works on philosophy and machines. 


\section{Remarks on science and its paradigm structure: science in context}

On Aristotelian paradigm. Aristotelian science generally consists of a series of propositions deductively ordered and further propositions are consequences of the previous ones. The axiomatic method is an auto-closed system of science: only the problems that can be deduced from the axioms or from already proved propositions can be solved in a rigorous manner. Science is seen as a closed system inside which no external datum can be accepted and the common and intuitive knowledge cannot be exploited. ${ }^{5}$ Each discipline is governed by specific axioms (Aristotle, 1853, Posterior Analytics, Book II, Ch. XIX; Aristotle, 1949). Aristotle, particularly, considered the postulates as the basic propositions which are common to every science. They are evident, true, necessary and are different from proper principles, which instead are propositions belonging to a particular theory:

It is also evident that if the propositions of which a syllogism consists are universal, the conclusion of such a demonstration, and in short of the demonstration of itself, must necessarily be perpetual. There is not then either demonstration, nor in short science of corruptible natures, but so as by accident, because there is not universal belonging to it, but sometimes, and after a certain manner. But when there is such, it is necessary that one proposition should not be universal, and that it should corruptible, corruptible indeed, because the conclusion will be so if the proposition is so, and not universal, because one of those things of which it is predicated will be, and another will not be, hence it is not possible to conclude universally, but that it is now. [...] The demonstrations and sciences however of things frequently occurrent, of the eclipse of the moon, evidently always exist, so far as they are such, but so far as they are not always, they are particular, and as in an eclipse, so also is it in other things. ${ }^{6}$

it is impossible to demonstrate the proper principles of each thing, for they will be the principles of all things, and the science of them the mistress of all (sciences). [...] Demonstration however is not suitable to another genus, except as we have said, geometrical to mechanical or optical, and arithmetical

\footnotetext{
For example, one can take into account problems with the incompleteness of a theory based on the axiomatic method. Based on deductive and axiomatic presentation of the arguments, it leaves no room to so-called common knowledge. Thus, it appears as a closed system of science, that is, scientifically speaking, it does not permit exchanges of whatever subject with other systems.

6 "Things Which are subject to Change are incapable of Demonstration per se", see Aristotle, 1853, Posterior Analytics, Book I, Ch. VIII, 263, line 3, Vol. I.
} 
to harmonical demonstrations. (Aristotle, 1853, Posterior Analytics, Book I, Ch. IX, 265, line 8)

I call those principles in each genus, the existence of which it is impossible to demonstrate. What then first thing, and such as result from these signify, is assumed, but as to principles, we must assume that they are, but demonstrate the rest, as what unity is, or what the straight and a triangle are. It is necessary however to assume that the unity and magnitude exist, but to demonstrate the other things. (Emphasis in italics by the author; Aristotle, 1853, Posterior Analytics, Book I, Ch. X, 266, line 1)

In particular, the principles of science deal with the ontological universe of that science, even if they do not determine such a universe:

Proper principles, again, are those which are assumed to be, and about which science consider whatever are inherent per se, as arithmetic assumes unites, and geometry points and lines, for they assume that these are, and that they are this particular thing. (Aristotle, 1853, Posterior Analytics, Book I, Ch. X, 266, line 20)

On Euclidean paradigm. It can be interpreted as an application of Aristotelian paradigm to a specific discipline-geometry. Its structure mainly needed Necessary elements and Non-necessary elements, Propositions and Corollaries. Here (Fig. 3) is an example:

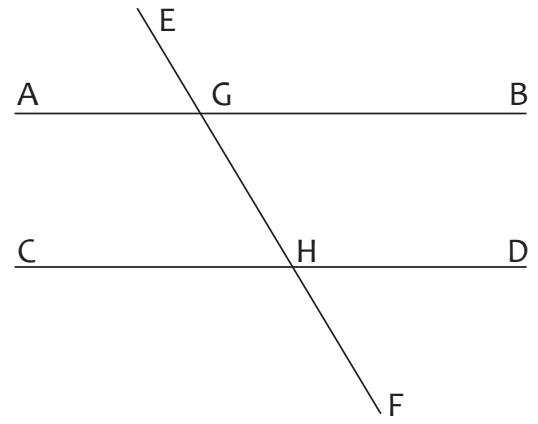

Figure 3. Proposition XXIX
Proposition XXIX. A straight line falling across parallel straight lines makes the alternate angles equal to one another, the external (angle) equal to the internal and opposite (angle), and the (sum of the) internal (angles) on the same side equal to two right angles. (Euclid, 2008, 32, cl. 2, parenthesis by the translator; also see Euclid, 1782, Book I, Theorem XXIX, 29, line 1) ${ }^{7}$

\footnotetext{
In order to show it, he used particularly the following proposition: Book I, Theorem 13, Postulate V, Book
} I, Theorem 15, Common notion I-II, Book I, Theorem 13, Common notion I. 
Raffaele Pisano

Paolo Bussotti

The main assertion to prove is:

$$
A G H=G H D
$$

An absurdum proof follows. ${ }^{8}$ Let us suppose, for hypothesis

$$
A G H>G H D \text { and adding } B G H,
$$

an inequality then follows:

$$
A G H+B G H>G H D+B G H .
$$

Therefore, we have:

$$
G H D+B G H<180 .
$$

But this is absurd because the two lines were supposed to be parallel, therefore, for the fifth postulate, the angle $G H D+B G H=180$. Hence the hypothesis $A G H>G H D$ is false. The reasoning is analogous if we supposed $A G H<G H D$. This theorem, in its ease, represents with a good paradigm how an axiomatic deductive system works and what the logic of the ad absurdum reasoning is: there are two accepted data, which, respectively, belong to what Euclid called Common notions and Postulates: 1) the fourth common notion (if equal things are added to different things, the results of the addition are different); 2) the fifth postulate. There is an ad absurdum hypothesis: $A G H>G H D$. Working on the two accepted data, we realize that this hypothesis is in contradiction with an accepted truth (the fifth postulate), hence it has to be refused. Therefore, because of the principle of tertium non datur - a logical axiom, that is applicable to every science, not only to geometry (see the difference posed by Aristotle) - the proposition $A G H=G H D$ is true (given that $A G H<G H D$, as told, is false because of the same reasoning as the one expounded). In the following (Table 1), a historicalepistemological comparison between main items in the two approaches to the science is proposed:

8 In the Elements 163 arguments presented by an ad absurdum reasoning: Book I (Propositions: 4, 6, 7, 14, 26, 27, 39, 40), Book III (Propositions: 1, 2, 4-8, 10-13, 16, 18, 19, 23, 24, 27), Book IV (Propositions: 4, 8, 13), Book V (Proposition: 18), Book VI (Propositions: 6, 26), Book VII (Propositions: 1-3, 20-24, 28, 29, 31, 33-36, 39), Book VIII (Propositions: 1, 4), Book IX (Propositions: 10-14, 16-20, 30, 31, 33, 36), Book X (Propositions: 2, 4, 13, 16, 26, 28, 29, 42-47, 79-84, 111), Book XI (Propositions: 1-3, 5, 7, 13, 14, 19, 23), Book XII (Propositions: 2, 5, 10-12, 18), Book XIII (Propositions: 2, 3, 18). 
Table 1. On Aristotelian-Euclidean paradigm of science

\begin{tabular}{|c|c|}
\hline Aristotelian & Euclidean \\
\hline $\begin{array}{l}\text { A Greek mathematical } \\
\text { treatise consists of a series of } \\
\text { propositions deductively ordered } \\
\text { always forward: the propositions } \\
\text { are always consequences of the } \\
\text { previous ones. } \\
\text { The axiomatic method is an } \\
\text { auto-closed system of science: } \\
\text { only the problems that can be } \\
\text { deduced from the axioms or } \\
\text { from already proved propositions } \\
\text { can be solved. } \\
\text { No common knowledge. As an } \\
\text { auto-closed system of science } \\
\text { well structured. }\end{array}$ & $\begin{array}{l}\text { Necessary elements: } \\
\text { Definitions or Assumptions or Terms } \\
\text { not proved that often precede the } \\
\text { Propositions. } \\
\text { Axioms or Common Notions. } \\
\text { Non-necessary elements: } \\
\text { Implicit assumptions: introduced ad hoc } \\
\text { as requests to proof certain Propositions. } \\
\text { Propositions: introduced as logical units } \\
\text { associated with proofs. } \\
\text { Simple Propositions: without use of the } \\
\text { conditional verb. } \\
\text { Non-simple Propositions: use } \\
\text { conditional verb. } \\
\text { Corollaries: }{ }^{9} \text { considered as a direct } \\
\text { consequence of a theorem. }\end{array}$ \\
\hline
\end{tabular}

On Archimedean paradigm. Archimedes (287-212 BC) was an influential author for Renaissance mathematicians ${ }^{9}$ according to two main traditions. First, the humanistic tradition, adhering strictly to philological aspects, followed by Willem van Moerbeke (1215-1286), Regiomontanus (1436-1476) and Federigo Commandino (1509-1575). Second, the pure mathematical tradition followed by Francesco Maurolico (1694-1575), Luca Valerio (1552-1618), Galileo Galilei (1564-1642) and Evangelista Torricelli (1608-1647). Based on previous works (Pisano \& Capecchi, 2010a,b) we can claim that the Archimedean scientific approach to geometry is different from the Euclidean one. The object

\footnotetext{
9 A corollary typically follows a theorem. However, we remark its subjective use in scientific theories. For example, a Proposition B is a corollary of a Proposition A if B can be readily deduced from A or is selfevident from its proof, but the meaning of 'readily' or 'self-evident' varies depending upon the author and context.
} 
is different, because Archimedes mainly deals with metric ${ }^{10}$ aspects, which was quite new; also, the aim is different, being more oriented towards solving practical problems. Furthermore, when Archimedes deals with science, his approach is even farther from Euclid's geometry. The theory's organization is different, because Archimedes does not develop the whole theory axiomatically, but sometimes he uses an approach for problems, characterized by reductio ad absurdum. Furthermore, the epistemological status of the principles is different. ${ }^{11}$

- Archimedean principles are not always as self-evident as those of the Euclidean tradition are and may have an empirical nature. Some of the Archimedean principles have a clear methodological aim, and though they may express the daily feeling of the common man, they have a less cogent evidence than the principles of Euclidean geometry. We wish to offer two examples: let us consider On the Equilibrium of Planes and the seven axioms posed at the beginning of the first book. We analyze the first and the seventh axiom: in the first one Archimedes claims that equal weights posed at equal distances from the fulcrum of the lever are in equilibrium and the equal weights posed at different distances from the fulcrum are not in equilibrium, but the lever inclines towards the weight which is at a greater distance. This axiom is exactly based on the daily feeling of the common man concerning equilibrium. We adhere at the idea that this feeling derives from iterated-both individual and common-experiences and not from an a priori structure of our mind. For sure, this axiom does not get the same level of evidence as Euclid's axioms. The divergence from Euclid's axioms is far more apparent in the seventh axiom where Archimedes establishes that every figure with a concave perimeter has its centre of gravity in its internal part. This axiom can appear evident only to people with a certain — practical or theoretical—experience in statics. It is far from Euclidean evidence.

10 Alongside, but quite different from Euclidean Stoicheiosis tradition of mathematics (rigour and logical structure of mathematical) Elements, a metric approach by Greek mathematicians (mainly Democritus, and then Eudoxus) was provided more or less in the same period. The latter stressed the relationships between geometrical measurements (solids, shapes, areas) and theorems-formulas. Archimedes was one of the mathematicians who adopted the metric approach in Measurement of a Circle, Quadrature of the Parabola, On the Sphere and Cylinder, On Conoids and Spheroids, On Spirals, On the Method, and the relevant On the Equilibrium of Planes (Pisano, 2009a,b,c; 2011; Pisano \& Capecchi, 2014). We are perfectly aware that, from a mathematical point of view, the Euclidean geometry is metric, while, for example, the projective geometry-dealing only with the graphic properties of the figures - is exactly graphic and not metric. We have used the word metric to indicate the fact that in Archimedes there are explicit formulas to calculate the surfaces and the volumes, while in Euclid there are formulas to compare the volumes of different figures, but the formulas for surfaces and volumes are not explicit and they were not the aim of the Elements.

11 With regard to the two traditions see also Pisano and Bussotti, 2014b. On the axiomatic during seventeenthcentury mechanics see Bertolini and Meli, 2010. 
- Archimedes was the first scientist to set rational criteria for determining centres of gravity of bodies and his work contains physical concepts formalized on mathematical basis.

- In Book I of the On the Equilibrium of Planes, Archimedes (in Heath, 2002), besides studying the rule governing the law of the lever, also finds the centres of gravity of various geometrical plane figures (Clagett, 1964-1984; Archimedes, 1881).

The concept of equilibrium and the determination of the centres of gravity rely upon specific calculations and mathematical procedures aiming at including different geometric configurations. ${ }^{12}$ Some parameters can be expressed by relations between numbers/interpreted by a ratio. In On the Equilibrium of Planes statics is rational and seems a new approach to science based both on empirical assumptions and on mathematical and geometrical proofs/iterations (i.e. reductio ad absurdum proofs). Therefore, statics was not presented as a purely abstract and axiomatic theory in Aristotelian-Euclidean style. This also depends on the nature of statics: this discipline deals with quantities, which are not only geometrical sizes, but are referred to in the external world, too. Archimedes realized that, for such branches of science, a mere deductive-abstract approach is not possible. The axioms have to express some properties of the external world which are considered primitive and, hence, not demonstrable. Thus, it is necessary to highlight that Archimedes was not an ante litteram empiricist: he was convinced that the basic principles had to be clarified and that the reasoning had to be deductively correct, but he was aware that the principles in science could not get the same evidence and origin as in Euclidean geometry.

From a historical point of view, it is worth remarking that Leibniz fully understood the difference between the Euclidean (and more generally, the mathematical) paradigm and the Archimedean paradigm. For, in 1715, at the beginning of his correspondence with Clarke, in his second writing, Leibniz highlighted that mathematics is based on the logical principles of identity and non-contradiction, whereas Archimedes, when establishing the laws of equilibrium, resorted to a different principle, that is the principle of sufficient reason, which is a metaphysical principle, because the mere mathematical and logical principles are not enough for a research on physics. In Leibniz's conception, the metaphysical principles are the necessary basis to deduce the physical principles, and, more in general,

12 In the Renaissance, Archimedean techniques were proposed to replace the section of the balance with a body of known mass and applying it in the middle (Pisano \& Capecchi, 2010a). 
the principles of every entity, which is not a mere logical-mathematical object. ${ }^{13}$

Coherently with the described picture, we find in Archimedes no definition of centre of gravity, because, in statics, the centre of gravity has to be assumed as a primitive concept (Pisano, 2007). Rather, Archimedes proposes methods in order to calculate them by means of rational criteria.

In the following (Table 2), a historical-epistemological comparison between the main items in the two approaches to the science is proposed:

Table 2. On Aristotelian-Archimedean paradigm science

\begin{tabular}{|l|l|}
\hline Aristotelian approach & Archimedean approach \\
\hline $\begin{array}{l}\text { The (idea of) centre of gravity } \\
\text { as a (dynamical) point, which } \\
\text { naturally moves towards the } \\
\text { centre of the Earth. }\end{array}$ & $\begin{array}{l}\text { Equilibrium criteria are based } \\
\text { on geometry theory. }\end{array}$ \\
$\begin{array}{l}\text { Principle of virtual velocity } \\
\text { (Aristotelian) and Principle of } \\
\text { virtual displacements (Jordanus } \\
\text { de Nemore) which include the } \\
\text { geometrical-arithmetical basic } \\
\text { form of the law of the lever. }\end{array}$ & $\begin{array}{l}\text { The equilibrium criteria claim } \\
\text { that a body is in equilibrium } \\
\text { state, if its common centre of } \\
\text { gravity cannot descend (itself) } \\
\text { for any of (its) possible motion. }\end{array}$ \\
$\begin{array}{l}\text { Gravitas secundum situm. }{ }^{14} \\
\text { (i.e. Jordanus de Nemore, } 13^{\text {th }} \\
\text { century) }\end{array}$ & $\begin{array}{l}\text { Centre of gravity for a system of } \\
\text { bodies calculated by means of } \\
\text { rules placed a priori. }\end{array}$ \\
\hline
\end{tabular}

On the heritage. ${ }^{14}$ The Greek conception of mechanics is revived in the Renaissance, with a synthesis of Archimedean and Aristotelian roots (Pisano \& Capecchi, 2014). This is best represented by Mechanicorum liber by Guidobaldo del Monte who reconsiders Mechanics by Pappus Alexandrinus, maintaining that the original purpose was to reduce simple machines to the lever. Particularly, after Tartaglia, and somehow their heirs, Giovanni Battista Benedetti, Guidobaldo del

13 For the Leibniz-Clarke correspondence, see Ariew, 2000 and Bussotti, 2014, in press.

14 In Supposition III de Nemore makes a generic assertion, for which a body weighs the more, the more directly it goes towards the centre of the world. He implies that 'heaviness' depends not only on the body, but also on its possible, or virtual, motion. In Supposition IV the meaning of Supposition III is specified, with the introduction of the locution gravitas secundum situm — gravity according to position — (de Nemore $1565,3 \mathrm{r}$; see also arguments on that, 4rv) a body is heavier than another, by position, when its descent is less oblique. On this problem, see the forthcoming Pisano and Capecchi, 2014. 
Monte and Galilei follow. Benedetti made important contribution to the analysis of natural motion of bodies. In statics, he made it clear and universally known that the effect of a force depends on the distance of its line of actions from the fulcrum. Nowadays this result is called the law of static moment. Guidobaldo del Monte attempted the restoration of Greek mechanics in the spirit of Pappus Alexandrinus, whose work was published by Federico Commandino, basing it on an Archimedean approach. He attempted, however, a synthesis with the Aristotelian approach of subalternate science in which physical aspects were clearly present. For example, when studying balance, he treats of a physical body and not simply a geometrical figure, giving substance also to the fulcrum, which for Archimedes was a simple geometrical point. Del Monte's mechanics was not only a science of the principles of equilibrium of weights on a balance. It was rather a science of machines, and, even if the equilibrium was crucial as well, the role of the displacement of the bodies was examined as the main element (Pisano \& Capecchi, 2014).

During the Renaissance, mechanics was a theoretical science and it was mathematical, although its object had a physical nature and social utility. Medieval texts in Latin and Arabic diverted from the Greek and Renaissance texts mainly because they divide mechanics into two parts. In particular, alFarabi (ca. 870-950) differentiates between mechanics in the science of weights and that in the science of devices (Pisano \& Capecchi, 2014). The science of weights refers to the movement and equilibrium of weights suspended from a balance and aims at formulating principles. The science of devices refers to applications of mathematics to practical use and to machine construction. In the Latin world a process similar to that connoting the Arabic world occurred. Even here, a science of movement of weights was constituted, namely Scientia de ponderibus (Brown, 1967-1968). Besides this, there was a branch of learning called mechanics, sometimes considered an activity of craftsmen, other times of engineers (Scientia de ingeniis). In the Middle Ages, various treatises on the Scientia de ponderibus circulated in Latin (Pisano \& Capecchi, 2013; 2014): some were Latin translations from Greek or Arabic, a few were written directly in Latin. Among them, the most important are the treatises attributed to Jordanus De Nemore, Elementa Jordani super demonstratione ponderum (version E), Liber Jordani de ponderibus (cum commento) (version (P), Liber Jordani de Nemore de ratione ponderis (version $\mathrm{R}$ ). They were the object of comments up to the $16^{\text {th }}$ century. The distribution of the original manuscript is not well known; what is certain is that Liber Jordani de Nemore de ratione ponderis (version R) was finished by Tartaglia and published after Tartaglia's death in 1565 by Curtio 
Troiano as Iordani Opvsculum de Ponderositate. Tartaglia is well known for the resolution of third-degree equations and his Discussions with Girolamo Cardano (1501-1576). Tartaglia (1536; 1554; Pisano \& Capecchi, 2014) is also known as editor of classical authors: Italian translation of Euclid's Elements titled Euclide Megarense (Venice, 1543). Tartaglia produced crucial and important contributions to mathematics, physics, and to the application of architecture. Tartaglia's contribution on mechanics can be divided into two parts, the former concerning what today is called statics, the latter concerning what today is called dynamics (Capecchi \& Pisano, 2008). Statics is developed by following the approach of Scientia de ponderibus. Tartaglia dedicated Books VII and VIII of his famous text Quesiti et inventioni diverse to statics. Book VII recalls a question of Mechanical Problems, Book VIII takes inspiration from Book 1 of Liber Jordani de Nemore de ratione ponderis, and is both an epitome and a paraphrase of it. Tartaglia's writings, however, contain many novelties and hence can be considered original.

\section{Concluding remarks}

The very conclusion of this paper will be written at the end of the second part. However, it is appropriate to summarize the itinerary we have traced up to now: the distinction between the Euclidean paradigm and the Archimedean paradigm has been posed because it is useful in an enquiry on the relations between mathematicsscience-constructions of machines: the Euclidean paradigm seems to be alien from every practical implication. This is true as far as the structure of the Elements is concerned, because it is well known that a serious line of research thinks that the origin of Euclid's Elements is in the practical problems of measuring areas. While Archimedes deals with physics - and especially when he highlights the properties of the lever-the implications to the machine theory are evident: for the lever itself is a machine. Therefore, Archimedes's laws (Archimedes [1897] 2002) concerning the lever are probably drawn from the properties of a machine and the theorems should explain some further properties of this machine which could be potentially useful for application. Only in the context of a science connected to machines, it makes sense to pose the problem between science and constructions of machines. Because of this, the distinction between the two paradigms is so important in our research: if there were only Euclidean paradigms, construction of machines and mathematics would be necessarily separated. The thing becomes interesting if Archimedean paradigm exists. The influence of Archimedean science-during a 


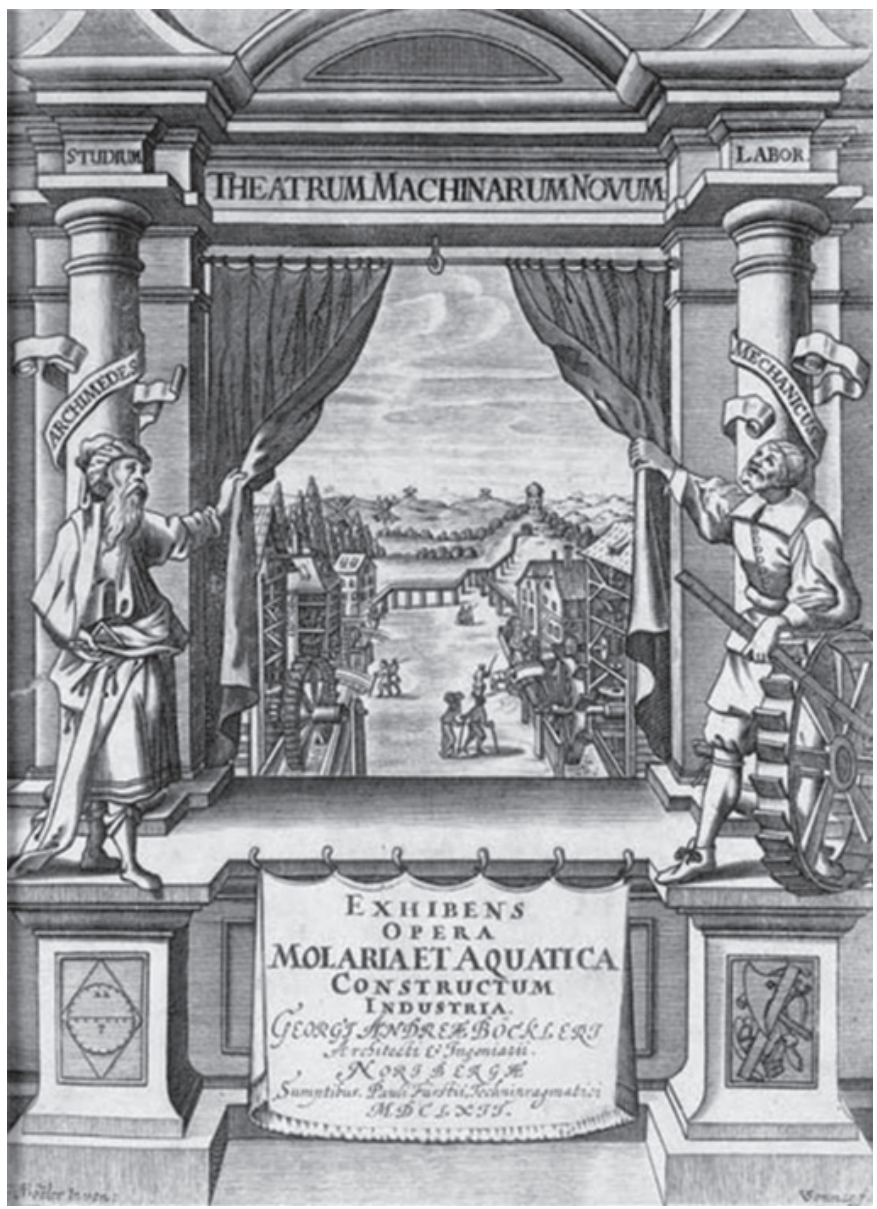

Figure 4. A frontispiece from Böckler's Theatrum Machinarum Novum (1661).

Note: This frontispiece is significant. The book discusses hydraulics. From the picture, it is clear that the author considers Archimedes (represented on the left side) the theoretical "father" of hydraulics. Let us consider the word Studium written over Archimedes. Whereas the Mechanicus (on the right side) is the one who applies the precepts of Archimedes. Let us remark the work Labor, written over Mechanicus. Significantly, the author refers to Archimedes and there is no mention either of Aristotle or of Euclid.

period in which machines were considerably improved — becomes a fundamental and intriguing datum in our research (Fig. 4). For one could think that the improvement of machines and the spread of Archimedean science were directly linked. While we think, and we try to prove in our paper, that such a direct link does not exist, even if, certainly, an indirect link subsists because the rediscovery of Archimedes was a decisive step in the research of the scientists who also provided 
Raffaele Pisano

Paolo Bussotti

important theoretical improvement to machine theory. However, the problem is exactly the complex and not easy relation between the theorists of machines and the constructors of machines.

\section{Acknowledgments}

We want to express our gratitude to the two anonymous referees for precious comments and helpful suggestions.

\section{References}

Archimedes (1881), Opera Omnia cum Commentariis Eutocii. E codice florentino recensuit, latine uertit notisque ilustrauit J.L. Heiberg, Lipsiae: in aedibus B. G. Teubneri.

([1897]2002), On the Equilibrium of Planes in T. Heath (ed.) The Works of Archimedes, New York: Dover Publications Inc., pp. 189-220.

Ariew, R., ed. (2000), G. W. Leibniz and Samuel Clarke: Correspondence, Indianapolis/ Cambridge: Hackett Publishing Co. Inc.

Aristotle (1853), The Posterior Analytics, Book II, Chapter XIX, in Octavius Freire Porphyry Owen (ed.) The Organon, Or Logical Treatises, of Aristotle, London: Bohn.

- (1949), Aristotle's Prior and Posterior Analytics. A Revised Text with Introduction and Commentary by W. D. Ross (ed), Oxford: The Oxford University Press.

— (1984), The Complete Works of Aristotle, ed. by J. Barnes, Princeton, NJ: Princeton University Press.

Bacon, F. (1857-1874), The Works of Francis Bacon, vol. IV, ed. by J. Spedding, R. L. Ellis \& D. D. Heath, London.

Bertoloni Meli, D. (2010), 'The Axiomatic Tradition in 17 ${ }^{\text {th }}$-Century Mechanics', in M. Dickson \& M. Domski (eds.) Synthesis and the Growth of Knowledge, Chicago: Open Court, pp. 23-41.

Böckler, G. A. (1661), Theatrum Machinarum Novum, Nürnberg: Christoff Gerhard für Paul Fürst.

Brown, E. J. (1967-1968), The Scientia de Ponderibus in the Later Middle Ages, Ph.D. dissertation, University of Wisconsin.

Bussotti, P. (2014, in press), 'The planetary theory of Leibniz: A complex itinerary related to Keplerian inspiration, new physical principles and metaphysical convictions.'

Capecchi, D. \& Pisano, R. (2008), 'La meccanica in Italia nei primi anni del Cinquecento. Il contributo di Niccolò Tartaglia', in Proceedings of XXV SISFA Congress, Milano: University of Milano. 
— (2010a), Scienza e tecnica nell'architettura del Rinascimento, Roma: CISU.

Carnot, L. (1786), Essai sur les machines en general, Dijon: Defay. (1803), Principes fondamentaux de l'équilibre et du movement, Paris: Deterville.

Clagett, M. (1964-1984), Archimedes in the Middle Ages, Madison-Philadelphia, Memoirs of the American Philosophical Society, vols. 1-5, tomes 1-10, Oxford: Clarendon Press.

Duhem, P. M. M. (1905-1906), Les origines de la statique, vols. 1-2, Paris: Hermann.

Euclid (1782), Euclid's Elements of geometry from Latin translation Commandine, by Cunn S., Strahan et al. ed., London.

(2008), Euclid's Elements of Geometry. The Greek text of J. L. Heiberg (1883-1885) from Euclidis Elementa, edidit et Latine interpretatus est I. L. Heiberg, in aedibus B. G. Teubneri 1883-1885, Edited and provided with a modern English translation by R. Fitzpatrick. Retrieved from http://farside.ph.utexas.edu/euclid.html [accessed Sep 2014]

Gille, G. (1966), The Renaissance Engineers, Cambridge, MA: MIT Press.

Heath, T. L., ed. (2002), The Works of Archimedes, New York: Dover Publications Inc.

Koyré, A. (1965), Newtonian Studies, Cambridge, MA: The Harvard University Press. http://dx.doi.org/10.4159/harvard.9780674181861

Kragh, H. (1987), An Introduction to the Historiography of Science, Cambridge: The Cambridge University Press. http://dx.doi.org/10.1017/CBO9780511622434

Kuhn, S. T. (1962), The Structure of Scientific Revolutions, Chicago: The Chicago University Press.

Mach, E. ([1883]1974), The Science of Mechanics. A Critical and Historical Account of its Development, transl. by T. J. McCormack, $4^{\text {th }}$ edition, La Salle: The Open Court $\&$ Merchant Book.

Pisano, R. (2007), 'Brief history of centre of gravity theory. Epistemological notes,' in M. Kokowski (ed.) Proceedings of the $2^{\text {nd }}$ ESHS Congress, Krakow, Poland, pp. 934-941.

(2009a), 'On method in Galileo Galilei's mechanics,' in H. Hunger (ed.) Proceedings of ESHS $3^{\text {rd }}$ Conference, Vienna: Austrian Academy of Science, pp. 147-186.

(2009b), 'Continuity and discontinuity. On method in Leonardo da Vinci's mechanics,' Organon, no. 41, pp. 165-182.

- (2009c), 'Galileo Galileo. Riflessioni epistemologiche sulla resistenza dei corpi,' in E. Giannetto, G. Giannini \& M. Toscano (eds.) Relatività, Quanti Chaos e altre Rivoluzioni della Fisica, Rimini:Guaraldi Editore, pp. 61-72.

(2011), 'Physics-Mathematics Relationship. Historical and Epistemological notes,' in E. Barbin, M. Kronfellner \& C. Tzanakis (eds.) European Summer University: History And Epistemology in Mathematics, Vienna: Verlag Holzhausen GmbH-Holzhausen Publishing Ltd., pp. 457-472. 
- (2014a, in press), A Bridge between Conceptual Frameworks, Science, Society and Technology Studies, Dordrecht: Springer.

(2014b, in press), 'A Development of the Principle of Virtual Laws and its Framework in Lazare Carnot's Mechanics as Case Study.' Submitted to Studies in History and Philosophy of Science.

Pisano, R.; Agassi, J. \& Drozdova, D., eds. (2015, in press), Hommage to Alexandre Koyré. Hypothesis and Perspective within History and Philosophy of Science. Dordrecht: Springer.

Pisano, R. \& Bussotti, P. (2012), 'Galileo and Kepler. On Theoremata Circa Centrum Gravitatis Solidorum and Mysterium Cosmographicum,' History Research, vol. 2, no. 2, pp. 110-145.

- (2014b, in press), 'The Emergencies of Mechanics and Thermodynamics in the Western Society during $18^{\text {th }}-19^{\text {th }}$ Century', in R. Pisano \& D. Capecchi (eds.) Tartaglia's Science Weights and Mechanics in XVI Century. Selections from Quesiti et invention diverse: Books VII-VIII, Dordrecht: Springer.

(2014c, in press), 'Fibonacci and the Reception of the Abacus Schools in Italy. Mathematical Conceptual Streams and their Changing Relationship with Society.' Submitted to Almagest.

Pisano, R. \& Capecchi, D. (2010a), 'On Archimedean Roots in Torricelli Mechanics,' in M. Ceccarelli \& S. Paipetis (eds.) Proceedings of the Genius of Archimedes, Dordrecht: Springer, pp. 17-28.

_ (2010b), 'Galileo Galilei: Notes on Trattato di Fortificazione,' in A. Altamore \& G. Antonini (eds.) Galileo and the Renaissance Scientific Discourse, Roma: Edizioni nuova cultura, pp. 28-41.

- (2013), 'Conceptual and Mathematical Structures of Mechanical Science in the Western Civilization around the $18^{\text {th }}$ Century,' Almagest, vol. 4, no. 2, pp. 86-121.

- (2014, in press) Tartaglia's Science Weights and Mechanics in XVI Century. Selections from Quesiti et invention diverse: Books VII-VIII, Dordrecht: Springer.

Pisano, R. \& Casolaro, F. (2011), 'An Historical Inquiry on Geometry in Relativity. Reflections on Early Relationship Geometry-Physics (Part One),' History Research, vol. 2, no. 1, pp. 56-64.

Pisano, R. \& Gaudiello, I. (2009), 'Continuity and discontinuity. An epistemological inquiry based on the use of categories in history of science,' Organon, no. 41, pp. 245-265.

Popplow, M. (1998), Neu, nützlich und erfindungsreich. Die Idealisierung von Technik in der frühen Neuzeit (Cottbuser Studien zur Geschichte von Technik, Arbeit und Umwelt 5), Münster \& New York: Waxmann.

- (2001), 'Mechanik, Maschinen und technische Sehenswürdigkeiten zu Beginn des 18,' Cardanus, vol. 2, pp. 75-99. 
(2002), 'The Concept of Machina in the Roman Period', in J. Renn \& G. Castagnetti (eds.) Homo Faber: Studies on Nature, Technology, and Science at the Time of Pompeii, Roma: L'erma di Bretschneider, pp. 83-90.

(2003), 'Hydraulic Engines in Renaissance Privileges for Inventions and Theatres of Machines,' in A. Fiocca, D. Lamberini \& C. Maffioli (eds.) Arte e Scienza delle Acquenel Rinascimento, Venezia: Marsilio, pp. 73-83.

- (2004), 'Neu, nützlich und erfindungsreich. Die Ingenieure der Renaissance als Schrittmacher der modernen Deutung von Technik,' in G. Engel \& N. C. Karafyllis (eds.) Technik in der Frühen Neuzeit - Schrittmacher der europäischen Moderne, Frankfurt am Main: Vittorio Klostermann, pp. 336-355.

(2010), Technik im Mittelalter, München: C. H. Beck.

Tartaglia, N. (1537), La noua scientia de Nicolo Tartaglia: con una gionta al terzo libro, Venetia: per Stephano Da Sabio.

([1554]1959), La nuova edizione dell'opera Quesiti et inventioni diverse de Nicolo Tartaglia brisciano. Riproduzione in facsimile dell'edizione del 1554, A. Masotti (ed.), Brescia: Commentari dell'Ateneo di Brescia, Tipografia La Nuova cartografica.

(1565), Iordani Opusculvm de Ponderositate, Nicolai Tartaleae Stvdio Correctum Novisque Figvrisavctvm, Venetiis, Cvm Privilegio Traiano Cvrtio: Apvd Curtivm Troianvm. M D Lxv.

Raffaele Pisano (Italy, 1970) earned his master's degree in physics and then specialized education in physics and mathematics at the University Federico II, Napoli, Italy; PhD at the University of Roma La Sapienza. He is qualified lecturer-researcher in history of physics, history and epistemology of science, science \& society studies at the University of Lille1, France. Since 2011, he acts as vice president of the Inter-Divisional Teaching Commission (DLMPS/IUHST). He is former head of the Research Centre for the Theory and History of Science, University of West Bohemia in Pilsen, Czech Republic. Pisano has authored more than one hundred publications (books and journals). The most recent publications are: Lazare and Sadi Carnot. A Scientific and Filial Relationship (2014, 2nd ed., Dordrecht: Springer) with Charles Coulston Gillispie; The Dialectic Relation between Physics and Mathematics in the XIX ${ }^{\text {th }}$ Century (2013, Dordrecht: Springer) co-edited with Evelyne Barbin. Forthcoming publications include: Tartaglia's Science of Weights and Mechanics in Sixteenth Century. Selections from Quesiti et inventioni diverse: Books VII-VIII (Dordrecht: Springer) with Danilo Capecchi; Newton's Principia "Jesuit" Edition: The Tenor of a Huge Work, Accademia Nazionale Lincei-Rendiconti Matematica e Applicazioni 2014, vol. 25, pp. 1-32 with Paolo Bussotti). More info at fr.linkedin.com/pub/raffaele-pisano/6/a11/a61/

Paolo Bussotti received his PhD degree in history of science from San Marino University in 1996. He got an Alexander von Humboldt fellowship in 2003-2005 at the Ludwig-Maximilians-Universität, Munich, to work on the history of number theory. He 
Raffaele Pisano

Paolo Bussotti

has also worked for the Kepler Kommission, Bavarian Academy of Sciences, Munich. In 2008-2010 he was the director of the Centro Studi Enriques, Livorno, Italy. Recently he spent a period as visiting lecturer at the Research Centre for the Theory and History of Science, Dept. of Philosophy and science education, West Bohemia University, Pilsen, Czech Republic. He also got an Alexander von Humboldt fellowship at the Berlin Academy of Sciences to work on Leibniz's planetary theory. Research fields: history and philosophy of science and mathematics, particularly the period 1500-1800, and mathematics. 